\title{
Scripta
}

Revista Internacional de Literatura i Cultura Medieval i Moderna

\section{La llengua de Carles Riba: el cas de Guillot, bandoler}

\section{The language of Carles Riba: the case of Guillot, bandoler}

ISABEL TURULL isabel.turull@uniroma1.it

Università di Roma - La Sapienza

\begin{abstract}
Resum: En l'àmbit d'un estudi sistemàtic sobre la llengua de Carles Riba, n'analitzem aquí un conte primerenc. Guillot, bandoler, publicat probablement cap al 1918, representa la primera incursió de l'autor en la narrativa per a infants, en un moment en què la fixació de l'ortografia i la normativa fabrianes encara es troba en evolució. Hi veiem, doncs, un llenguatge que aspira a la correcció però que és al mateix temps espontani, mentre podem relacionar-ne alguns trets característics amb la voluntat d'adherir-se a un gènere narratiu concret. En aquest sentit, la tradició rondallística admet la presència de termes de registre més elevat en un context de mímesi literària del llenguatge parlat, cosa que justificaria la presència en aquest text d'expressions com: «pujaven [...] tan instruïdets»; al costat de: «la bèl lica munió».
\end{abstract}

Paraules clau: Riba, narrativa, gènere, registre

Abstract: As a part of a sistematic study on Carles Riba's language, we analyse in this paper one of his first short stories. Guillot, bandoler represents the author's first attempt to write a children's tale: it was published in 1918, in a moment when Fabra's works on Catalan's orthography and normative were still evolving. It presents, thus, a language that tends to correctness but that is also spontaneous, while we can link some of its characteristic features to the author's will of adhering to a concrete literary genre. The tale's tradition allows the presence of terms that belong to a more elevated language in a context of literary mymesis of the spoken language, and that would justify the presence in this text of expressions like: «pujaven [...] tan instruïdets»; next to: «la bel lica munió».

Keywords: Riba, narrative, genre, register 
Carles Riba, «home essencial», segons Joan Ferraté o Miquel Dolç (Ferraté 1984: 41; Dolç 1986: 27), «lingüista» i fins i tot 《l'únic poeta català científicament preparat en lingüística, almenys fins a l'època en què començà a escriure...» segons Triadú (1954: 11), corrector de les traduccions dels clàssics de la Fundació Bernat Metge (incloses les elaborades per Coromines), model de qualitat lingüística en les seves pròpies traduccions (Alberich 1993), ha estat considerat per una part de la crítica, sobretot a partir de la seva mort i dels comentaris que llavors va fer-ne Joan Coromines (recollits a Coromines $1974^{2}$ [1971]: 394), com un ròssec per a l'evolució natural de la llengua catalana.

Un altre exemple d'aquest corrent antiribià podrien ser les tesis iconoclastes de Pericay i Toutain els anys 90 (Pericay - Toutain 1997²), encara que van tenir un ressò limitat, però fins i tot autors com Gabriel Ferrater, grans admiradors de l'obra ribiana, en van criticar l'estil, especialment en la prosa: «Perquè [...] Riba era poc destre, tenia poca traça en el maneig de la llengua [...]» (Ferrater 1979: 17); i més endavant: «...s’ha de tenir un enorme control de la llengua que en podríem dir col loquial, de la llengua del diàleg, de la llengua ordinària. Ara bé: de control d'aquesta mena de llengua, Riba no en va tenir mai» (Ferrater 1979: 115).

Sembla evident, doncs, que cal analitzar de manera sistemàtica la llengua de Carles Riba. El que presentem aquí és una part d'un treball més ampli en què ens hem fixat en la prosa ribiana, i dins d'aquesta, en els contes per a infants. És en aquesta mena de prosa on es posa a prova la capacitat de l'autor d'escriure de forma simple i efectivament el mateix Riba en parlava considerant els seus contes: «uns utilíssims exercicis de simplicitat» $(O C / 5: 270)^{1}$. Com veurem, Guillot, bandoler, el primer conte publicat pel nostre autor, resulta especialment interessant en aquest sentit, tant des del punt de vista del moment en què apareix (1918) com per les informacions que ens proporciona sobre la llengua d'un Riba encara ben jove.

\section{Notes d'història textual}

A l'edició de Marfany de les Obres completes ribianes (1965-1967), dins l'apartat de la narració, trobem en primer lloc segons l'ordre cronològic Les aventures d'En Perot Marrasquí, mentre Sullà, en una nova edició publicada vint-i-cinc anys més tard (1992), seguint també l'ordre cronològic, posa aquesta obra en segon lloc, darrere Guillot, bandoler. Les raons de l'un i de l'altre són justificables segons els criteris que exposen: Marfany té en compte la primera data de publicació tout court, i Sullà la primera data de publicació com a volum solt i complet. Marfany considera rellevant que el Perot Marrasqui es comencés a publicar el 1913, tot i que no aparegués com a volum fins al 1924, mentre Sullà només considera que Guillot, bandoler va aparèixer complet abans, segurament cap al 1918.

Allò que ens ha fet triar, doncs, aquest «primer» conte, no ha estat només el fet que fos efectivament

\footnotetext{
1 Citem, si no diem altrament, per l'edició de Sullà de l'Obra Completa de Carles Riba. La narrativa es troba al volum 5, a partir d'ara $O C / 5$ (veg. bibliografia).
} 
el «primer» dels publicats en vida de Riba, cosa que com veiem és discutible, sinó que per una banda era un text breu, cosa que per a la nostra anàlisi representava una comoditat, i per altra banda que, com ens diu Sullà, Riba no el va recollir en cap volum posterior i no va tenir, doncs ocasió d'afegirhi modificacions. Per aquest motiu, a més, podem limitar la nostra recerca a la forma amb què el text va aparèixer el 1918 per a l'editor Muntañola. Sortosament podem trobar-lo reproduït en línia dins el Corpus Literari Digital elaborat per la Càtedra Màrius Torres²: http://www.catedramariustorres. udl.cat/materials/biblioteca/index.php

Farem tanmateix alguns comentaris respecte a l'edició última del text, que va curar Enric Sullà dins les Obres Completes de 1992 (OC/5). El curador hi indicava els criteris que havia seguit, en gran part, segons deia, obligat pel format de la col lecció que no li permetia per exemple incloure-hi un aparat crític. Afirmava també que en el cas concret de Guillot, bandoler havia respectat tant l'ortografia com el lèxic i la morfologia (Sullà 1992b: 64), però que no s’havia pogut estar de corregir alguns «errors mecànics». Si bé és cert que Sullà hi respecta algunes formes com ara «trapacer》o 《dugues》, que comentarem més avall, les seves correccions són molt més abundants del que ens podríem esperar pel que diu en la seva nota. Així, corregeix sistemàticament l'article determinat femení davant de vocal àtona:

- l'innocència, l'indisciplina > la innocència, la indisciplina

Corregeix l'ortografia d'alguns mots:

- agavellador $>$ agabellador

- mig dia > migdia

- despiedat $>$ despietat

- davassall $>$ devessall

- assenglotada > assanglotada

- altissonant $>$ altisonant

- mutuu $>$ mutu

- càrregs $>$ càrrecs

- treient $>$ traient

- munior > munió

2 La pàgina exacta és la següent:

http://www.catedramariustorres.udl.cat/materials/biblioteca/visor.php?acronim=guil\&titol=Guillot $\% 20$ bandoler\&any $=1918 \& a c r \_a u t o r=r i b a \& n o m \_a u t o r=C a r l e s+R i b a \& z o o m=\&$ tipus $=\_a u t o r s \& p o s=0$ 
I també fa algunes correccions de puntuació o de sintaxi (eliminació de punt després del subjecte; correcció de vacil lacions en l'ús de «pen»/«per a»).

Per tots aquests motius, i malgrat la indubtable utilitat de l'edició de Sullà en el seu moment, l'anàlisi lingüística d'aquest text hauria quedat falsejada si haguéssim considerat innecessari, refiant-nos de les afirmacions del curador, consultar l'edició original.

\section{El gènere}

Per col locar en primer lloc l'obra dins el gènere que li pertoca, direm que és evident, malgrat que la fórmula d'inici no sigui en aquest cas alguna de les tradicionals «vet aquí que una vegada», o altres, que Riba pretén escriure alguna cosa que recorda una rondalla i aquest serà un condicionant d'alguns dels aspectes que veurem. També cal especificar que no parlem de «rondalla» en el sentit circumscrit a la tradició catalana, sinó en el més general de text adreçat a infants dins de la tradició que inclou, per exemple, les obres dels germans Grimm pel que fa al folklore germànic. Pensem que les traduccions del mateix Riba d'aquests autors apareixeran l'any següent de la publicació de Guillot, bandoler, amb el títol de Contes d'infants i de la llar (Editorial Catalana, 1919 i 1921).

Pel que fa a les fonts de l'obra, la crítica s'ha decantat a veure la inspiració de Guillot, bandoler en el Roman de Renard o en altres poemes medievals amb animals com a protagonistes (Rovira 1988: 450; Valriu 1994: 106). Efectivament el protagonista, en Guillot, és a dir el mascle de la guineu, ens fa pensar de seguida en el goupil que l'autor anònim anomenava Renard en el poema medieval francès. Com també ens recorden els seus paral lels del text francès altres diversos noms de personatges, com el del gall Cantaclar sense anar més lluny, idèntic al Chantecler francès. De tota manera, el to del nostre conte és molt diferent del del Roman de Renard. Si veiem en tots dos una transposició del món humà al món animal, el que importava en el primer era sobretot la ridiculització dels forts davant de l'astúcia dels febles, i Renard acabava en tot cas sortint sempre bé de les seves aventures. Al conte de Riba, en canvi, com bé diu Sullà (1992a: 18), importa sobretot la moral final : «Qui la fa, ve un dia que la paga», i Guillot és un personatge negatiu que acaba executat a la plaça pública per les seves malifetes amb gran alegria de tothom.

La presència d'una moral final ens fa pensar en altres gèneres de contes amb animals com ara les faules, i especialment La Fontaine, de qui Riba admirava «la vibració justa dels seus mots» (Turull 2014: 54), però no hem d'oblidar les rondalles d'animals de la tradició catalana. En aquestes és cert que la guineu normalment surt ben parada de les seves males accions, com el goupil del Roman de Renard, mentre és el llop en canvi qui sovint acaba pagant-les amb la mort. A la rondalla del llop fredolic, per exemple, la guineu enreda el seu company perquè s'escalfi al forat de la xemeneia de la barraca de les cabres i així aquest acaba ben malament: «tot plegat, distret, girant-se i pergirant-se, 
ell que cau a una marmita d'aigua calenta que les cabres tenien al foc per rentar-se els peus, i allí va morir» (Bertran 1989: 196). Trobem també algun cas en què és la guineu qui acaba malament, per exemple a la rondalla en què enreda un cotoliu i l'ocell es venja. Després d'amagar uns gossos sota la palla, fa creure a la guineu que els ulls dels animals són raïms i la convenç perquè se’ls mengi, de manera que els gossos la maten: «La guineu que es tira a la palla per menjar-se els raïms, i els gossos que l'atrapen i la maten» (Bertran 1989: 207).

Per veure quines són les característiques que defineixen el gènere de la rondalla i quines afecten el nostre text, ens basem en l'estudi clàssic de Cristina Lavinio (1980). Pel que fa a la «fiaba» ${ }^{3}$, que ella oposa per una banda al «mito» i per l'altra a la «leggenda», i que creiem que podem relacionar amb la nostra «rondalla», veiem com el text de Riba n'acompleix els determinants: caràcter profà i no sacre, caràcter acrònic dels fets narrats, i fets fantàstics percebuts com a tals, presentats al lector amb intenció purament lúdica. Així mateix, la fórmula d'obertura, que com hem dit no és la tradicional, s'inscriu en el ventall més ampli de fórmules que normalment són de tancament, i que com ens diu Giovanna Cerina (1980: 121), representen uns: «modi di mediazione tra il mondo fiabesco e il mondo quotidiano, attraverso la simulazione di una sorta di contemporaneità tra l'io emittente e i personaggi».

En el nostre cas, amb l'ús del verb en present: «Encara els caus ne van plens de les malifetes de Mestre Guillot...», es crea un espai en què trobem en un mateix pla el temps de la situació narrativa i el temps remot del conte. Tant la fórmula d'obertura com la de tancament són característiques del gènere, $i$ serveixen tradicionalment per crear aquesta frontissa entre el món real i el món màgic en què tot és possible, que els animals parlin, $\mathrm{O}$, com veiem en altres contes del nostre autor, que els nens paguin alguna malifeta convertint-se en gat o en ruc.

Seguint encara l'estudi de Lavinio (1980: 100) ens fixem ara en les característiques lingüístiques del gènere i veiem, en primer lloc, que la llengua d'aquestes narracions recorda d'alguna manera la llengua oral, tot i que es tracta en realitat d'una llengua elaborada literàriament. No tots els trets lingüístics que l'estudiosa determina són rellevants en el nostre cas, però sí que ens sembla important en primer lloc la mímesi del llenguatge parlat, que es tradueix per exemple en el recurs al diàleg amb el lector: «Jo us el podria fer d'antuvi més antipàtic...» (OC/5: 69) i que Riba utilitza també a Sis Joans. En aquest sentit, no estem d'acord amb la consideració d'Albert Jané (2012: 382) que veu aquest tret com a característic d'un «escriptor moralista», sinó que per a nosaltres és simplement coherent amb el gènere en què s'inscriu.

En segon lloc i pel que fa a les qüestions lèxiques, Lavinio (1980: 101) nota la possibiltat de l'ús de termes connotats com a arcaics o literaris en textos com els que estem tractant: termes diferents dels que s’utilitzen en l'àmbit de la comunicació quotidiana, que en el cas de les rondalles catalanes

\footnotetext{
3 El terme italià «fiaba» no s'ha de confondre amb el semblant «favola», que correspondria al nostre «faula». La «fiaba» correspon en canvi a la nostra «rondalla».
} 
podríem relacionar amb substantius com «donzella» o adjectius com «formosa». Veurem en el cas de Riba com podem aplicar aquests conceptes.

\section{La llengua}

En el seu conte, Riba busca un to col loquial, però també hi barreja alguns arcaismes i cultismes. Encara que considerem que la delimitació del registre col loquial té un marge d'arbitrarietat, ja que la realitat és un continum lingüístic infragmentable (Payrató 1988: 46), cal dir també que és molt evident en algun cas el contrast entre el to general d'un text i l'aparició de lèxic corresponent a un registre diferent ${ }^{4}$. Per altra banda, insistim que en el nostre cas ens trobem amb una mimesi literària del llenguatge parlat, i no pas amb una situació real de col loquialitat.

Parlarem, doncs, d'arcaismes en el sentit de termes que podien sonar antiquats ja a l'època d'escriptura del conte que ens ocupa, $i$ de cultismes en el sentit de termes pertanyents a un registre més formal que el del context. Veurem a més com Riba també utilitza mots que pertanyen a llenguatges més tècnics o d'especialització que tampoc no s'escaurien en una situació col loquial. Creiem que si més no en molts d'aquests casos es tracta d'un recurs estilístic coherent amb el gènere dins el qual es col loca el nostre text.

El registre col loquial es mostra en l'ús de múltiples marques de subjectivitat que recorden l'origen oral del gènere ${ }^{5}$

interjeccions: «Déu me’n guard!» $(O C / 5: 69)$

datius ètics: «ja me’n veié la bèl lica munió avançant» (OC/5: 72)

diminutius: «pujaven [...] tan instruïdets» (OC/5: 69)

Però sobretot en les construccions idiomàtiques i en alguns dels termes triats, que veurem tot seguit.

Tot i que es considera la utilització de construccions idiomàtiques, locucions o frases fetes, com un recurs típic del registre col loquial, cal dir que si consultem el Diccionari de locucions i frases fetes (Raspall - Martí 1996), o també altres diccionaris més moderns i més ambiciosos, com el Diccionari de sinònims de frases fetes (Espinal 2006), veiem com no totes les expressions que hi apareixen donarien aquest to a un determinat context. Així hi podem trobar gairebé de costat: «d'amagatotis», que efectivament ens esperaríem en un context col loquial o informal, $\mathrm{i}$ «damunt dit», que pertany clarament a un registre escrit o formal. Tindrem com a punt de referència, doncs, el primer d'aquests volums,

\footnotetext{
4 Payrató parla per exemple de «grotesques barreges de castellanismes i arcaismes en la parla corrent» (1988: 48).

5 Citem per comoditat del lector per l'edició de Sullà OC/5 si no ho indiquem altrament i si aquesta coincideix amb la primera edició.
} 
però prendrem en consideració només les construccions idiomàtiques que efectivament podem classificar dins un registre col loquial.

En el conte que estem estudiant trobem mostres abundants d'aquestes construccions:

amb prou feines $(O C / 5: 69)$

el cas és que $(O C / 5: 69)$

anar per les branques $(O C / 5: 70)$

allò que se'n diu (OC/5: 70)

sense embuts $(O C / 5: 71)$

marxà com una seda $(O C / 5: 71)$

La veritat on sigui $(O C / 5: 73)$

i a més algunes presenten un cert grau de creativitat per part de l'autor. Així trobem: «caigués qui caigués》(OC/5:70), (en lloc de la més freqüent «caigui qui caigui»), o bé: «cara a cara, i l'arma a la pota》 $(O C / 5: 69)$.

També cal citar dins aquest grup de construccions idiomàtiques les parèmies i els refranys. Com veurem, no podem classificar els exemples que trobem en el nostre text com a parèmies, ja que no tenen un ús antic, però sí com a refranys, ja que la forma és sentenciosa i el líptica i expressen un pensament a manera de judici: «ja és cosa sabuda que la gent d'una certa edat s'estimen més deu marrades que una drecera》 $(O C / 5: 70)$. Aquesta dita representa ben bé el saber popular, sempre conservador, i encara que no l'hem trobada en els diversos reculls de parèmies que hem consultat, si més no de forma literal, és evident que Riba l'està utilitzant com a refrany. Un segon exemple d'aquest tipus de construcció s'allunya encara més de la forma fossilitzada de la parèmia, però recorda altre cop la saviesa popular: «aqueixa trista llei que multiplica la cogula entre els blats i el lladre entre la gent de bé» (OC/5: 69).

Altres trets col loquials es poden veure en la tria del lèxic pròpiament dit, per exemple: «pujar», pel verb més neutre «créixer», dins la frase «pujaven tan ben nodrits» $(O C / 5:$ 69), o bé «donar», dins «i com que l'ofici donava» (OC/5: 69), pels més tècnics «produir»o «rendir» i també alguns desplaçaments emfatitzants dels elements de l'oració, típics del llenguatge oral, per exemple: «Els sermons, no cal dir que avorreixen la mainada» (OC/5: 70).

Per altra banda, Riba, coherent amb la tradició de la rondalla descrita per Lavinio, barreja en el seu 
text alguns termes connotats com a no col loquials i hi trobem sobretot cultismes: «bèl lic» $(O C / 5$ : 71), «morigerat» (OC/5: 69), etc; o també tecnicismes que mostren una imitació del llenguatge de la justícia i de la política: verbs com «al legar» $(O C / 5: 71)$, expressions com «podem prescindir de parlar» (OC/5: 71), «es declara insuficient» $(O C / 5: 72)$, o substantius com «els menors» $(O C / 5: 70)$, «peremptorietat» $(O C / 5: 71)$, etc.

Alguns termes no poden ser classificats com a cultismes, però pertanyen a un registre especialitzat no gaire freqüent en els contes per a nens. Del llenguatge de la carnisseria en sentit propi, per exemple, trobem aquí: «palpissos» (OC/5: 69) (per al qual dins el CTILC hi ha un total de 27 resultats); «tatxó» (OC/5: 72), en lloc del fabrià «tatx», del qual parlarem més endavant; «cansalada» (OC/5: 72). Aquesta contaminació entre diversos registres, en aquest cas entre un registre bèl lic i el més casolà de la carnisseria, és utilitzat per Riba com a recurs humorístic.

Altres trets del lèxic de l'obra no es poden considerar conseqüència del gènere $\mathrm{i}$ ens donaran, doncs, informació concreta sobre l'idiolecte de l'autor. En primer lloc, analitzem alguns termes que Riba utilitza i que Fabra no va recollir en el DGLC.

- trapacer (OC/5: 69): no apareix, tampoc amb formes ortogràfiques diferents, al DGLC, però sí al DCVB i al DIEC2 amb la forma «trapasser».

- salta-camins (OC/5: 69): al DGLC només apareix «saltamarges», com a «lladre de camps», i igualment al DCVB. Al CTILC només hi trobem una ocurrència de 《salta-camins》, en una obra de Joaquim Ventalló de 1968.

- tatxó (de cansalada) (OC/5: 72): no apareix als reculls lexicogràfics sota aquesta forma, però és un derivat de «tatx», «Porció d'una cosa que hom en separa per comprovar-ne la qualitat» (DGLC i DIEC2).

- viuda $(O C / 5: 70)$ : Riba utilitza aquí la forma que després Coromines defensarà aferrissadamament sense aconseguir incloure-la a la segona edició del DGLC. L'any en què surt publicat el conte aquesta era la forma més freqüent segons el CTILC i per altra banda el propi Fabra l'acceptava amb la indicació «h.» («habitualment») al Diccionari ortogräfic de $1917^{6}$. De tota manera, dins l'obra de Riba recollida al CTILC i també a la correspondència que no hi és inclosa aquest és l'únic cas en què trobem aquesta forma i no «vídua». Riba sol seguir, doncs, disciplinadament les indicacions fabrianes, però aquí no ho fa.

- dugues (OC/5: 70). Trobem aquesta forma del català familiar del femení de «dos», molt estesa al parlar viu de Barcelona, Girona, etc (DECat,III,192), però no acceptada per Fabra.

6 Hem consultat la versió recollida a l'OC de Fabra, volum 4, que correspon a la segona edició, de 1923. 
Alguns termes presenten un ús dubtós i plantegen problemes per altres motius.

\section{- vianda:}

DCVB, 1. Menja, comestibles; 2. llegum i hortalisses;

DIEC2, f. Menjar ${ }^{2}$ 1. «Es proveïren de prou vianda per al llarg viatge. Van servir les millors viandes de la comarca».

DGLC, nom genèric de tot allò que hom menja.

L'ús que en fa Riba és dubtós perquè recorda el sentit del «viande» francès, especialitzat exclusivament per a la carn:

«només de la vianda que sobrava a la seva nombrosa família en proveïa les tres botigues de caça i ocelleria més acreditades de la capital» (OC/5: 69).

Si en aquest cas no en tenim la certesa, cal dir que altres ocurrències d'aquest terme en altres contextos ribians també ens deixen aquest dubte; per exemple a l'Odissea, tant en la versió de 1919 com la de $1953^{7}$ :

«I en ser que el Cíclop s’omplí l'enorme ventrell de viandes humanes» (Odissea II, 1919, p. 17); «Quan el Cíclop per fi va haver-se omplert la gran panxa de viandes humanes» (Odissea 1953, p. 165)

Per altra banda, fent una recerca al CTILC, amb filtre cronològic 1914-1923, de 105 resultats trobats, n'hi ha alguns que mostren aquesta mateixa ambigüitat, i dos on clarament el sentit és el de «carn»:

«En estreta cautivitat, en aquarium per exemple, (la carpa) menja viandes i deixa per elles els grans i altres productes vegetals» (Francesc d'Assís Darder, Piscicultura industrial, 1915);

«100 grams de vianda magra donen 80 calories; 100 grams d'arroç, 345 calories; 100 grams de pa, 257 calories; 100 grams de patates, 98 calories» (J. Tarruella i Albareda, Higiene de l'alimentació, 1917).

És cert que tots dos casos representen el món de les ciències, on les influències lingüístiques poden ser diferents de les habituals.

Per altra banda, però, a l'Atles lingüístic del domini català (Veny - Pons vol. II 2003: mapa 386) a la pregunta semàntica sobre què vol dir el mot «vianda» les respostes són vagues a tot el territori, excepte a la zona d'influència francesa, on vol dir «carn»: això és, al Rosselló, al Conflent, al Capcir, a l'Alta Cerdanya (però no a Llívia), i al Vallespir. Curiosament, també a Cubells (Noguera).

Afegim a més que a la versió provisional del Diccionari Descriptiu de la Llengua Catalana (DDLC) que

7 La segona versió de l'Odissea de Riba recollida al CTILC és la d'editorial Alpha, de 1953. 
es pot consultar en línia aquesta accepció sí que hi és recollida.

- juí: Segons Coromines (DECat, IV, 934), aquesta és la forma més popular per a «judici», tot i que el lingüista també proposa una certa distinció sinonímica que de tota manera no seria rellevant aquí. Segons Veny (2007: 65), es tracta simplement d'un dialectalisme i efectivament, sempre segons Coromines (DECat, IV, 935), la forma usada per Riba actualment hauria deixat de pertànyer al llenguatge parlat en català central, però restaria plena de vigor no sols a València i a les Illes, sinó encara a Tortosa, d'on, recordem-ho, era originari el pare del nostre autor. La pregunta seria, doncs, si Riba utilitza «juí» com a forma marcada de registre popular, o bé com a dialectalisme pertanyent al llenguatge patern; en tot cas, a partir de 1919 ja no en trobem ocurrències en la seva obra.

Acabarem amb el grup de mots que representen diversos tipus de tractaments i que Riba usa per als diferents personatges, començant pel mateix Guillot, anomenat Mestre Guillot.

Cap d'aquests tractaments no es pot considerar genuí en català, i sobretot no ho és el «don» de «don Conill de Flairabrises», però tampoc no ho és ni tan sols el «Mestre» de «Mestre Guillot». Segons les definicions dels diccionaris, és «mestre» qui ensenya o és capaç d'ensenyar, o bé el menestral capaç de fer el seu ofici independentment i ensenyar aprenents (Diec2; GDLC; DGLC), però el tractament «mestre» només s'aplicaria a músics o artistes, a certs religiosos, o bé com a vocatiu per a un desconegut. És cert que al CTILC trobem molts exemples de la mateixa forma utilitzada per Riba al nostre conte: Sagarra parla de «mestre Adam» a la seva traducció de la Divina Comèdia (1947), i molts homes de la cultura són anomenats de la mateixa manera en múltiples publicacions, sense que hagin de ser necessàriament músics. El mateix Pompeu Fabra és anomenat sovint «Mestre Pompeu Fabra» en senyal de respecte, però ni tan sols el DDLC recull aquesta accepció.

Dit això, l'ús que en fa Riba en aquest conte es pot inscriure altre cop en la imitació de l'estil rondallístic. Per una banda, «mestre», «compare», «Missenyor», «Don», són termes connotats com a arcaics, i per l'altra recorden concretament algunes obres en les quals Riba s'inspirava, des del Roman de Renard a les faules de La Fontaine. Del primer, a més, pren la inspiració per als noms d'alguns personatges, el gall Chantecler i els dos fills de Renard, Percehaie i Malebranche, però sobretot la profusió dels diversos tractaments, «sire», «compère», etc; de La Fontaine no cal insistir en el famós «Maître Corbeau», traduït a més per Carner com a «mestre corb».

\section{Conclusions}

En aquest conte primerenc de Carles Riba ja veiem algunes de les característiques de l’idioma que

8 veg. La Fontaine, Faules, Editorial Catalana, Barcelona 1921; i l'edició més recent, a cura de J. Subirana, Faules, Destino, Barcelona 1995. 
utilitarà més endavant: la seva intenció és seguir les indicacions fabrianes, les quals, però, encara no han estat fixades, de manera que hi trobem algunes vacil lacions, sobretot pel que fa a l'ortografia de certs mots. Hi trobem també alguns termes que Fabra no recollirà al DGLC però Alcover al DCVB sí, com per exemple «trapacer» (al DCVB amb la forma «trapassen»); d’altres que són exclusius de Riba, com «salta-camins», calcat sobre «saltamarges»; trobem també algunes formes dialectals o localismes que Riba abandonarà en la seva obra posterior, com «juí»o «dugues».

Pel que fa a l'estil del conte, algunes de les tries lèxiques són coherents amb el gènere, cosa que justifica que s'hi barregin trets que donen al text un aire de col loquialitat amb alguns termes que pertanyen a un lèxic culte o bé especialitzat. Dins aquest apartat podem esmentar des de les referències als «palpissos», a verbs com «al legar», adjectius com «morigerat», «bèl lic», passant pels diversos tractaments, des de «Don» a «mestre», $\mathrm{O}$ «missenyor».

També trobem algun cas especial, com per exemple «vianda», mot que Riba utilitza amb una accepció que ni Fabra ni els altres diccionaris no recullen fins avui, però que sí que trobem al DDLC, en la seva versió encara consultable exclusivament en línia. En l'evolució posterior del llenguatge dels contes ribians, aquests casos especials es faran més freqüents i més difícils de justificar.

\section{Bibliografia}

Alberich, J. - Ros, M. (1993) La transcripció dels noms propis grecs i llatins, Barcelona, Ed. Enciclopèdia catalana, Biblioteca Universitària.

Bertran i Bros, P. (1989) Rondallari català, Josep M. Pujol (ed.), Barcelona, Editorial Alta Fulla.

Cerina, G. (1982) «La fiaba tra oralità e scrittura: aspetti semiotici», dins G. Cerina - C. Lavinio - L. Mulas (ed.), Oralità e scrittura nel sistema letterario. Atti del convegno. Cagliari, 14-16 aprile 1980, Roma, Bulzoni editore, pp. 115-131.

Coromines, J. (1974² [1971]) Lleures i converses d'un filòleg, Barcelona, Club Editor.

Dolç, M. (1986) "Carles Riba o la responsabilitat lingüística", dins Actes del Simposi Carles Riba, Barcelona, Publ. Abadia de Montserrat, Biblioteca Milà i Fontanals, 21, pp. 25-32.

Espinal, M.T. (2006) Diccionari de sinònims de frases fetes, 2 a ed. revisada, Barcelona, València, UAB Servei de publicacions, Publicacions U. de València, PAM (també consultable en línia;

http://ddd.uab.cat/pub/libres/2006/89642/Diccionari_sinonims_Espinal_a2006.pdf).

Ferraté, J. (1984) Un home essencial, "La Vanguardia”, 10-VII-1984, p. 41.

Ferrater, G. (1979) La poesia de Carles Riba, Barcelona, Edicions 62, col. "L'escorpí” 39. 
Jané, A. (2012) «La llengua de Riba en la narrativa infantil», dins Actes del III Simposi Carles Riba, a cura de C. Miralles, J. Malé, J. Pujol Pardell, Barcelona, IEC, pp. 381-389.

Lavinio, C. (1982) «La fiaba tra oralità e scrittura: aspetti linguistici e stilistici», dins G. Cerina - C. Lavinio - L. Mulas (ed.), Oralità e scrittura nel sistema letterario. Atti del convegno. Cagliari, 14-16 aprile 1980, Roma, Bulzoni editore, pp.. 91-114.

Payrató, L. (1988) Català col toquial. Aspectes de l'ús corrent de la llengua catalana, València, Universitat de València.

Perea, M. P. (2012) «La llengua de Carles Riba: de la correcció a l'estètica» dins Actes del III Simposi Carles Riba, a cura de C. Miralles, J. Malé, J. Pujol Pardell, Barcelona, IEC, Barcelona, pp. 349380.

Raspall, J. - Martí, J. (1996) Diccionari de locucions i frases fetes, Barcelona, Ed. 62.

Riba, C. (1992) OC/ 5, Obres completes/ 5, Narrativa, a cura d'E. Sullà, Barcelona, Ed. 62.

Riba, C. (1918) Guillot, bandoler, Barcelona, Ed. Muntañola.

Rovira, T. (1988) «La literatura infantil i juvenil», dins Riquer/Comas/Molas, Història de la literatura catalana, IX, Barcelona, Ariel, pp. 421-471.

Sullà, E. (1992) «Introducció: Les narracions de Carles Riba. Nota a l'edició», dins Carles Riba, Obres completes/5. Narrativa, a cura d'Enric Sullà, Barcelona, Edicions 62, pp. 7-65.

Turull, I. (2014) Teoria i praxi de la llengua literària en Carles Riba, Tesi doctoral, Barcelona, UAB.

Valriu, C. (1994) Història de la literatura infantil i juvenil catalana, Barcelona, Pirene.

Veny, J. (2007) «El Diccionari general de la llengua catalana: precedents, posterioritat, dialectalismes», dins Fabra, Obres completes, 5, dir. J. Mir - J. Solà, Barcelona, IEC, pp. 41-76.

Veny, J. - Pons i Griera, L. (2003) Atles lingüistic del domini català, II, Barcelona, IEC.

Sigles i referències de diccionaris

DCVB = Alcover, A. M. - Moll, F. de B. (1926-1962) Diccionari català-valencià-balear, 10 vols., Palma de Mallorca.

DECat = Coromines, J. (1980-1991) Diccionari etimologic i complementari de la llengua catalana, 9 volums, Barcelona, Curial - "La Caixa".

DGLC = Fabra, P. (1932) Diccionari general de la llengua catalana, Barcelona, Llibreria Catalònia. 
DIEC2 = Institut d'Estudis Catalans (2007) Diccionari de la llengua catalana, segona edició, Barcelona [etc], Edicions 62 [etc].

Bases de dades

Càtedra Màrius Torres

http://www.catedramariustorres.udl.cat/materials/biblioteca/visor.php?acronim=guil\&acr autor $=$ riba\&tipus $=$ autors\&nom autor $=$ Carles + Riba,

Guillot, bandoler, primera edició consultable en línia, Corpus Literari Digital de la Càtedra Màrius Torres, Universitat de Lleida.

\section{CTILC}

http://ctilc.iec.cat/

Corpus Textual Informatitzat de la Llengua Catalana.

DDLC

http://dcc.iec.cat/ddlc/index.asp

Diccionari Descriptiu de la Llengua Catalana. 